\title{
A Grounded Theory Study on the Academic Performance of Female Adolescents in the Context of Family Alcohol Addiction
}

\author{
Nina Aulmann and Simon Forstmeier* \\ Developmental Psychology and Clinical Psychology of the Lifespan, University of Siegen, Germany
}

*Corresponding author: Simon Forstmeier, Developmental Psychology and Clinical Psychology of the Lifespan, Institute of Psychology, University of Siegen, Adolf-Reichwein-Str. 2a, 57068 Siegen, Germany, Tel: +49-0-271-740-4020

\begin{abstract}
Background: It is estimated that about $10-20 \%$ of children and adolescents live with a parent with alcohol problems. Psychosocial consequences like difficulty concentrating or learning, and the development of maladaptive coping strategies lead to a higher risk of addiction and to further psychological disorders. The aim of the current study is to investigate the subjective consequences of pathological alcohol consumption on the learning behavior of adolescents and young adults at school.
\end{abstract}

Methods: Five qualitative interviews on the consequences of their parents' alcohol addiction were conducted with women aged between 16 and 24 years and evaluated with the Grounded Theory methodology.

Results: Two trajectories could be identified regarding the subjective learning behavior and academic performance. The first one includes ambitious learning behavior and compensation of performance, while the second one can be described as deteriorating learning behavior and decompensation of performance.

Conclusion: Compensation of performance due to psychosocial and emotional burden through parental addiction seems to be an intermittent coping strategy method of adolescents and young adults.

\section{Keywords}

Addiction, Adolescence, Academic performance, Coping, Mental health, Qualitative methodology

\section{Abbreviations}

CoAs: Children of Alcoholics; DGPs: Deutsche Gesellschaft Für Psychologie (German Association of Psychology)

\section{Introduction}

It is estimated that about $10-20 \%$ of children and adolescents live with a parent with alcohol problems $[1,2]$. When estimating the number of unreported cases, this number increases even more [3]. Previous studies investigated the prevalence of mental disorders and psycho-systemical consequences on children of alcoholics (CoAs). In the present study we concentrated on their learning behavior and performance at school. We assumed that addictive disorders within the family context lead to a decompensated and deteriorated academic performance. Furthermore, the attachment qualities of affected adolescents and young adults were investigated, because an insecure or disorganized attachment style often contributes to the development of addictive disorders.

\section{Mental and physical health of CoAs}

Previous research revealed significant differences between CoAs and controls with regards to several mental and physical health outcomes. CoAs show a higher risk of becoming alcoholics themselves and developing other mental disorders during the transition from adolescence to young adulthood. This was shown, for example, by Ulrich, Stopsack, et al. [4], who found that German CoAs had a 2.4 times increased risk of alcohol disorders ( $16.9 \%$ vs. $7.9 \%)$, compared to children of the same age with non-alcoholic parents. They also showed more affective disorders ( $18.1 \%$ vs. $8.8 \%)$ and more Cluster-B personality disorders, i.e., borderline, antisocial, histrionic, and narcissistic personality disorders ( $10.8 \%$ vs. $5.3 \%, p=0.075)$. Similar findings have been found in other countries, for example in Denmark $[5,6]$.

Serec, et al. [7] investigated various aspects of

Citation: Aulmann N, Forstmeier S (2019) A Grounded Theory Study on the Academic Performance of Female Adolescents in the Context of Family Alcohol Addiction. Int Arch Addict Res Med 5:031. doi. org/10.23937/2474-3631/1510031

Accepted: August 07, 2019: Published: August 09, 2019

Copyright: (C) 2019 Aulmann N, et al. This is an open-access article distributed under the terms of the Creative Commons Attribution License, which permits unrestricted use, distribution, and reproduction in any medium, provided the original author and source are credited. 
health-related lifestyle, e.g. time spent on physical activities, time spent on sedentary activities such as television and internet, and eating habits. CoAs reported significantly poorer health behaviors than controls.

The association between parental problem drinking and their children's problem drinking in young adulthood seems to be moderated by the quality of the relationship. Finan, et al. [8] found that the still existent social support of the parents reduces the strength of the association.

\section{Transmission process}

Various studies investigated the mechanisms of how alcohol addiction and related health problems might be transmitted from the parental to the child's generation. Pönsch (2012) [9] focused on pathological attachment of CoAs. He discussed the relationship between the dysfunctional behavior of addicted parents and the resulting attachment behavior of the children. He hypothesized that the parents' psychopathology constitutes difficult living conditions for their children, which may lead to pathological behavioral patterns or even addiction in adulthood. Pönsch (2012) [9] offered fundamental information about attachment behavior and addictions in the family, but did not discuss the academic consequences of these experiences. Similarly, Zobel (2017) [10] considered the psychosocial environment, including school only rudimentary. He described children's emotional instability, emotional neglect, arbitrariness of parental behavior, a lack of support, a lack of interest, and ambiguous limits in family settings.

The attachment style of CoAs is particularly impaired when they have also had traumatic experiences like physical and sexual violence. This often results in an insecure attachment style, and mental health problems like depression, suicidal tendencies, panic disorder, violence, substance abuse, sexual problems, eating disorders. Borderline personality symptoms are even more likely than in CoAs without traumatic experiences $[11,12]$.

Social and emotional competences such as emotion regulation are linked to the attachment style [13]. If the attachment style is impaired in CoAs, those competences will also be restricted. This was shown, for example, by Carle, et al. [14]. They investigated CoAs in a longitudinal study with a control group, and their prevalence rate with regards to social and emotional competences and found a lower level of these competences on average in CoAs. In both groups, the competences were negatively associated with internalized symptoms and positively with positive affect.

Werner, et al. [15] determined that although longitudinal studies about the development of CoAs are rare in community samples, they have become a major subject of scientific interest. Moreover, the authors could show that CoAs who did not become alcoholics them- selves received more social support during adolescence than children who suffered from alcohol dependence. This fact emphasizes the need to offer social support to families with alcohol problems.

\section{Learning behavior and academic performance}

A previous research on academic consequences of parental alcohol addiction mainly used the calculation of means in samples of CoAs compared with controls. For example, Serec, et al. [7] found that CoAs reported poorer school performance, and CoAs' families have higher unemployment rates and lower economic status. This was also found in other studies $[16,17]$.

Not only was academic performance in general investigated, but also cognitive functions underlying worse performance. For example, Bennett, et al. [18] investigated 64 children from 37 families with an alcoholic parent. These were compared with 80 children from 45 families without alcoholic parents with regards to intelligence, cognitive performance, as well as mental and physical disorders, impulsiveness, hyperactivity, social competence, learning problems and behavior. There were significant differences between the two groups with regards to cognitive abilities, performance, and emotional functions. However, the focus of this study was not on learning behavior and academic performance, but on general and multiple effects on mental functions.

The problem with the previous research strategy is that possible different typologies of academic performance in CoAs cannot be detected. This is the topic of the present study.

\section{Theoretical framework}

Several systematic reviews and meta-analyses on academic achievement in adolescence have been published so far $[19,20]$. Wang, et al. [20] organized all variables that were investigated to predict school achievement in a theoretical framework of six theoretical constructs: a) State and District Governance and Organization; b) Home and Community Educational Contexts; c) School Demographics, Culture, Climate, Policies, and Practices; d) Design and Delivery of Curriculum and Instruction; e) Classroom Practices; and f) Student Characteristics. The topic of the present study, alcohol addiction of parents, belongs to the home context (b), but is not mentioned as a variable that was investigated in any of the studies. The category of Home and Community Contexts belonged to the categories with the strongest mean association with school achievement. Similarly, Hattie [19] found that home variables such as socio-economic status and parental support of learning are associated with school achievement with moderate effect sizes. But again, the specific variable of family addiction was not included. Thus, there is a need to investigate the role of alcohol addiction of parents and its association with school achievement because it belongs to a 
category of variables that was found to be meaningfully related, but is as single variable not adequately investigated so far.

\section{Research question}

The current study attempted to contribute to the scientific research on the question of the consequences of parental pathological drinking on the learning behavior and academic performance of their children. The study focusses on the subjective experience of the children and does not include any physiological measures. Qualitative interviews were conducted with adolescents and young adults and analyzed with the grounded theory methodology. The study aimed to develop a model of the consequences of parental addiction on the adolescents' learning behavior. Thus, the research question was as follows: What are the consequences of the parents' pathological alcohol consumption on the subjective learning behavior and academic performance of the adolescents and young adults, considering their internalized attachment experiences? The hypothesis was that CoAs show a rather decompensated and deteriorated academic performance.

\section{Methods}

To answer the research question, the grounded theory approach [21] was applied. This method is a systematic approach of qualitative research and develops a theory that best describes the data obtained. In a circular process of comparing the interview data from different participants, core categories are developed which should lead to a typology beyond the data description and analysis.

\section{Participants}

The participants were recruited at psychotherapeutic practices and through the mailing list of the University of Siegen. People who were raised by addicted parents were asked to participate in a personal interview. All participants received a $€ 30$ voucher of a local shopping mall as an incentive to participate.

The sample consisted of five women aged between 16 and 24 years. No males answered the invitation to participate. Each participant in the study signed a declaration of consent before conducting the interview. In the case of an underage subject, this has taken over a custodial parent. The ethics commission of the German Association of Psychology (Deutsche Gesellschaft für Psychologie, DGPs) approved the study.

\section{Interview}

The audio recorded and semi-structured interviews lasted around 45 minutes. The interviews were divided into five sections to allow the comparison of the interviews and generate a free narrative mode.

1. First childhood memories: The participants were asked about their first childhood memories regard- ing their family situation. They also gave information about the addicted parent and his/her drinking behavior. The first section focused on early infancy until school entry.

2. Perception of the addiction problem: The second section was about the differences experienced between their own family and others. Furthermore, the participants were asked about the first time they realized about the parental addiction. This section aimed to explore the extent of the burden experienced.

3. Effects on learning behavior: This section referred to the consequences of the parental alcohol consumption on learning behavior at school.

4. Search for support: The fourth section was about the search for pedagogical or therapeutic support and the reason for this.

5. Current experience: The last section concerned the question of how the parental addiction changed the children's behavior at school, and which factors influenced their behavior positively or negatively.

The difference between questions 3 and 5 is that question 3 deals explicitly with the effects of parental drinking on school performance. Question 5 covers a range of general implications, including those that go beyond learning behavior and school life.

\section{Data analysis}

The data analysis was based on the grounded theory approach. The first step was to listen to the audio recorded interviews and read the notes which were written down during the interview. The audio data were transcribed with the f4transcript software (dr. dresing \& pehl GmbH, Marburg, Germany). Afterwards, memos were added to the transcriptions in order to document hypotheses and thoughts from the very beginning. The memos were supposed to make a continuous reflection and triangulation of the data easier. Use of the memory was compulsory during data analysis.

Following the rules of the grounded theory methodology, codes, e.g. keywords which appeared repeatedly in the transcript, were collected. These codes were used to find differences, common ground, and behavior patterns. The aim was to form categories based on these codes. The identified behavior patterns are subsequently called core categories. They are the basis to formulate typologies which represent the data precisely and analytically.

\section{Results}

Below, the interviews are summarized and the core categories and typologies are illustrated.

\section{Interviews}

First childhood memories: The participants did not 
have any problems talking about this topic and mainly depicted positive childhood memories. However, they also reported that they could not remember many things that happened due to their current age.

Perception of the addiction problem: There were no meaningful differences between the participants' answers. They reported the differences experienced between their own family and others. All participants expressed the wish to sometimes live in a different family setting. Each participant indicated that they first knew about the drinking problem and its extent during primary school (age 6 to 10). The intensity and quantity of the alcohol consumption was similar in all cases. Strong alcohol (e.g., liquor) was a frequent drink. One participant also reported parents' drug consumption in addition to the alcohol. The parents with alcohol problems were the mothers in two cases and the fathers in three cases. They were all classified as delta alcoholics [22], i.e., with physical dependence, loss of control, and inability to abstain.

Consequences for learning behavior: Two participants reported problems concentrating and excessive demands on their lives. Also, somatic consequences like stomachache and headache were reported, which prevented the participants from going to school. As a consequence of the parental addiction problem, two participants reported a worsening academic performance. These two participants on average only achieved satisfactory marks. In contrast, the other participants indicated very good marks and reported that they intentionally stayed away from home to avoid problems regarding the drinking behavior. The two participants with good marks also explained that they concentrated on school in order to forget the problems at home.

Search for support: None of the participants used social support during their schooldays. One participant was in contact with a consulting teacher due to an initiative by the school. Another participant contacted a social charitable organization, and had a few consultations that she considered helpful to her. The reason why the other participants did not ask for help was that they wanted to deal with the problems by themselves.

Current experience: All participants reported that the parental alcohol addiction influenced their learning behavior and academic performance. They declared that their school career would have proceeded differently without the problems at home. Additionally, the emotional burden and the negative social consequences would have been less.

\section{Categories and typologies}

Figure 1 and Figure 2 illustrate the circular process between the biography and external influential factors, i.e. the parents' alcoholism. The evaluation of the circular process showed two learning types: The performance decompensating type and the performance compensating (efficient) type. These results refute the hypothesis that there is only a decompensating learning type.

Performance decompensating type (Figure 1): Both participants of this category reported great difficulties concentrating and poor academic performance. They mentioned having suffered from the parental drinking problems, which sometimes meant that they could not sleep. The participants could not compensate for the emotional burden which had a negative influence on their academic performance. Furthermore, they assumed responsibility for their parents and took over their duties, e.g. in the household or taking care of their siblings, which also influenced their academic performance.

Performance compensating type (Figure 2): Three participants tried to distract from the family situation by concentrating on success at school. Coping with the difficult circumstances at home and meeting the requirements at school at the same time seemed to be a central, helpful, and structuring framework for the five participants. A central strategy for coping with the emotional burden was apparently to focus on efforts at school, and on the ambition to live a different life than their parents. However, the participants seemed not to consciously focus on the academic performance on purpose, but rather mentioned it as an unconscious process. Interestingly, some participants asked for therapeutic support after the interview. This may be due to the reactivated experience of the family situation during the interview.

All participants showed emotional manifestations and some participants cried during the interview. They expressed depressive symptoms especially while talking about the emotional situation of the addicted parent/ parents. They showed more empathy and compassion with the parents than focusing on their own needs and emotions. The participants experienced their own feelings and emotions intensely. Depressive symptoms were common in both types and could include sadness, loss of interest, social withdrawal; the depressive symptoms were more intense in the compensating type. They frequently experienced anxiety, confusion, sadness, anger and aggression, and internalizing emotions (e.g., sadness, anxiety) were more frequent than externalizing emotions (e.g., aggression, disinhibition).

Participants with the compensation of performance type predominantly showed adaptive behavior. To avoid emotions, some participants distracted themselves, for example, with homework or social interaction. This allowed them not to think about their situation at home. Two participants explained that they tried to distract themselves with school work, although they did not know why. Consequently, school needs to be considered a necessary distraction from the problems at home. 
It seemed to be difficult for the participants to identify their negative emotions during the interviews. One participant was angry about her parent and had physically attacked him/her in conflict situations. The aggressive and regressive situations were ambivalent toward the participants' wish to take the responsibility for their addicted parent (parentification). Therewith the participants avoided and minimized their emotional and everyday problems. Some of them unconsciously had the idea that good academic performance may later allow them to leave the responsibility behind and start their own life. They did not notice the emotional degeneration and, thus, did not work on it therapeutically. Being interviewed about the topic encouraged them to face their emotions and request for therapeutic support.

The interview made them realize some of their emotional problems. Furthermore, they were able to evaluate biographical events that happened early in life. On the one hand, some participants compensated their family problems by concentrating on their academic performance (Figure 2). On the other hand, some par- ticipants decompensated and presented problems concentrating on school demands (Figure 1).

\section{Discussion}

The results of the current study indicate two possible courses of academic performance in CoAs: A compensation of performance type, with good academic results, and a decompensation of performance type, with concentration problems and worsening academic results.

\section{Diverse school careers}

Previous research on their academic performance suggested a general disadvantage of CoAs compared to children of same age from non-alcoholic parents $[7,16,17]$. However, this research mainly used the calculation of means in samples of CoAs compared with controls. The problem with this research strategy is that possible different school careers in CoAs cannot be detected. This might be the reason for other findings that did not show any differences between CoAs and controls $[23,24]$.

\section{Context/intervening condition}

\begin{tabular}{|c|}
\hline Dependent, youthful, \\
object-related
\end{tabular}<smiles>C1CC1</smiles>

Causal condition

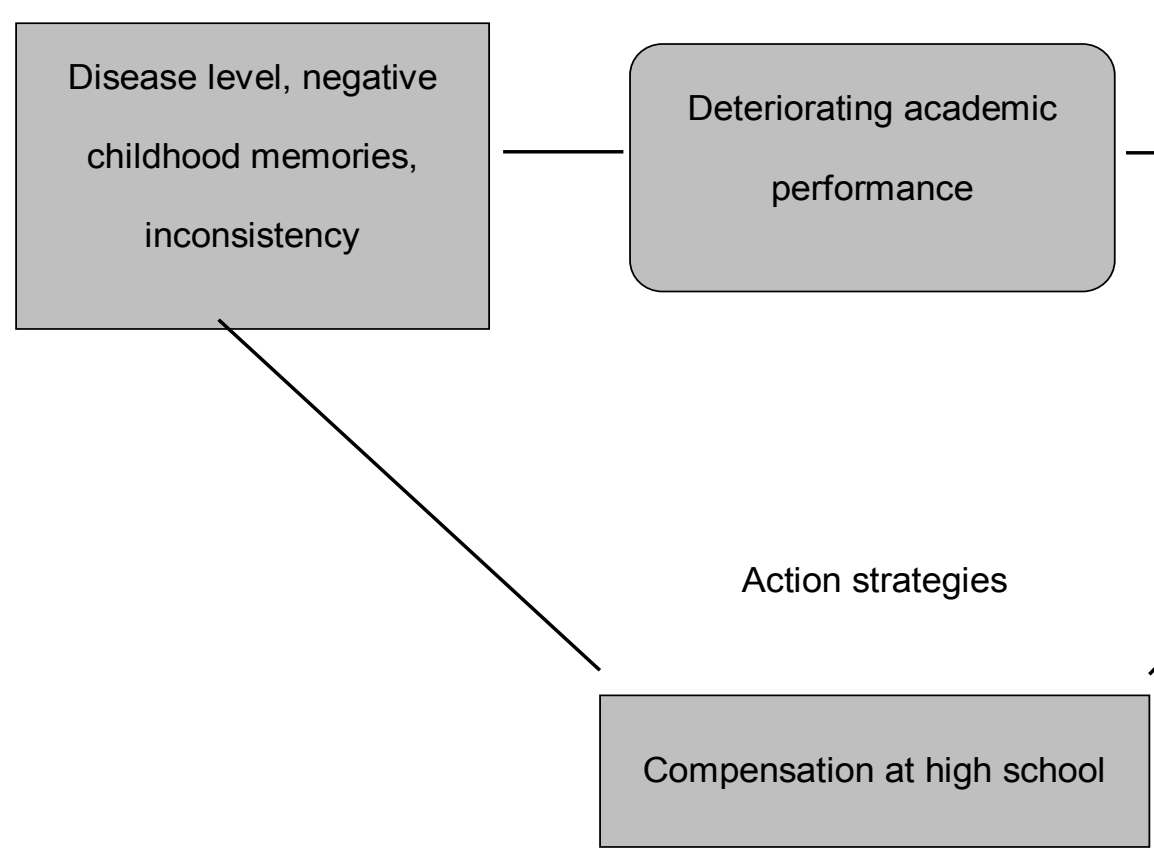

Development, biography, sociocultural background

\section{Consequence}

\section{Depressive} symptoms, fears, resilience, initiative

Figure 1: Relationship between the categories on the condition of decompensation of performance. 


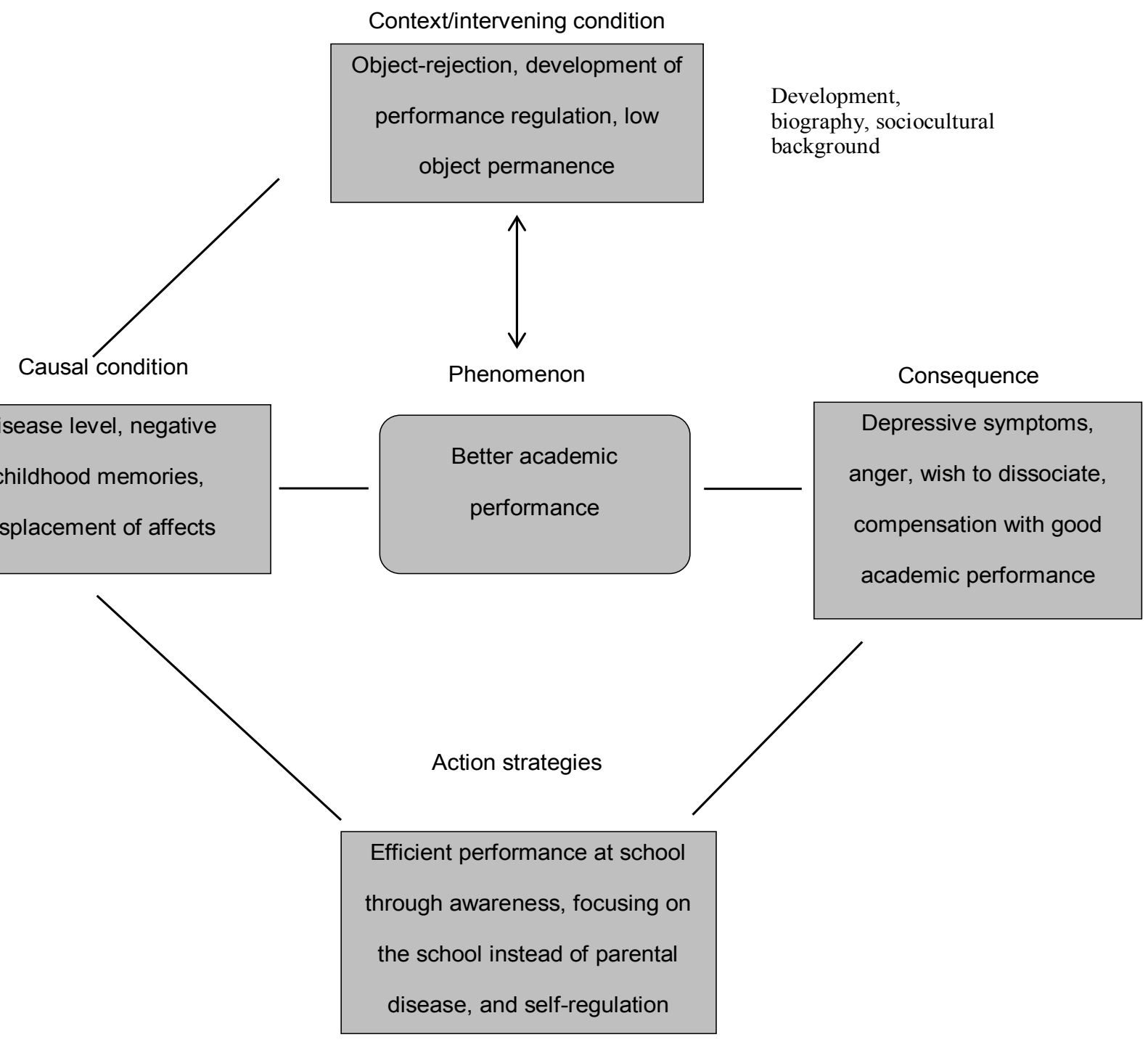

Figure 2: Relationship between the categories on the condition of compensation of performance.

The finding that not only worse, but also better academic performance could be a consequence of living as CoA can be explained by the immense resilience of children and adolescents [25]. In a systematic review on resilience of CoAs, various resilience factors were identified on four levels: individual, parental, familial and social [26]. On the individual level, CoAs experience less deteriorating consequences or positive consequences of the parental alcoholism if they are older [27], have more self-esteem [27], more self-regulation [28], a flexible temperament [29] or are optimistic [30]. On the parental and family level, a positive parenting style [31], the quality of relationship of the parents [32], a positive family climate [33], and supportive and caring family members [15] can constitute resilient factors for the CoA. On the social level, social support from friends, teachers and other important individuals can buffer against $\mathrm{CoA}^{\prime}$ 's negative experiences $[27,30]$. All these factors can be seen as a buffer against alcohol-related problems.

These factors might also impact the school career of CoAs. We found that individuals from the performance compensating type used focusing on efforts at school as a coping strategy in order to distract from the difficult situation at home. This strategy might reflect self-regulatory competence, optimism, and flexibility that resilient CoAs show. In addition, these individuals might have supportive friends and teachers that help them cope with the parental alcoholism, or are better able to make use of the existent friends and teachers. By contrast, less resilient CoAs might be less able to exploit the school context as a coping strategy to distract from parental alcoholism.

In a different line of research, one functional and four dysfunctional personality styles were found in CoAs, which reflect a similar distinction between positive and negative courses of development [34]. The functional personality style is called "Hyperconscientious/ High-functioning" and is described as "liked by others, articulate, and assertive", but also tending to "exhibit feelings of depression, guilt, and anxiety about living up to their own moral and ethical standards" (S. 491). This result supports our observation that the two CoAs with the compensating performance type are successful at 
school, but might still have emotional problems that are not met at home or at school and should be targeted by counselling services. The dysfunctional personality styles are called "Angry/Externalizing", "Awkward/Inhibited", "Emotionally Dysregulated", and "Sexualized/ Self-defeating" which all reflect some sort of pathological development.

\section{Practical implications}

The results of the study can be applied in school counselling, school prevention, and psychotherapy settings. It is necessary to assess the coping abilities and academic aspirations of CoAs very early on. Based on this information, counselling and psychotherapy goals can be adapted to the individual needs and competences. Individual counselling and therapy strategies seem to be very important, even in group approaches for prevention [35].

Prevention concepts should start as early as in kindergarten and should involve low-level public relations work. However, there is a lack of studies on the efficacy of such projects so far. Nevertheless, the German projects "Model Project Working with Children of Addicts Freiburg" (since 2003) and "Connect Hamburg" (20032005) illustrate that especially professionals in the education system can be trained in order to reach out to adolescents living in the aforementioned situation. Teachers should be taught to recognize and support these children.

There is a lack of prevention programs for CoAs in the school setting. For example, Jenson, et al. [36] illustrate basic strategies to offer preventive programs, including social support to children with deviant behavior. However, they did not account for CoAs. According to Schroeder (2009) [37], school has a unique opportunity to offer children and adolescents social and systemic support in a preventive way and in critical situations.

\section{Limitations}

The current study is a pilot study and gives direction to future research. One limitation is the small sample of five young female adults. No current schoolchildren were included in the sample, but adolescents and young adults provided information about their childhood and adolescence retrospectively. Further biographical interviews need to be conducted to obtain more extensive, valid and reliable data. Furthermore, a longitudinal study might provide further findings on the topic.

\section{Conclusions and directions for future research}

In this preliminary study, it was found that three out of five subjects performed well and good in terms of school performance, whereas two of five showed a pattern of poor academic performance. These findings show that the context of a family addiction can have positive and negative consequences on the adolescents' and young adults' academic performance. Often, dysfunctional behavioral patterns, oppositional or depressive disorders are consequences of the parental alcohol addiction. Additionally, the study aims to achieve a better understanding of processual and externalizing behavior as a reaction to the context of family addiction.

Our results encourage further investigation of the prognostic variables that might give the practitioner an indication of who is predestined to develop a decompensated performance and, thus, should receive more support than others. These findings form the basis for a future study, which aims to investigate whether certain variables (e.g., social support by the healthy parent, self-regulatory abilities and other personal resources) can predict a compensating and a decompensating type. Furthermore, longitudinal studies should investigate whether good school achievements are actually an effective method of compensating in the long run. These future studies should also use quantitative measures in order to quantify the effect size of the associations.

\section{Acknowledgments}

We would like to thank our participants who reliably and comprehensively participated in our study.

\section{Declarations}

This study was approved by the ethics commission of the German Association of Psychology (Deutsche Gesellschaft für Psychologie, DGPs). All procedures performed involving human participants were in accordance with the ethical standards of the institutional and/or national research committee and with APA ethical standards. Informed consent was obtained from all individual participants included in the study.

The study participants gave their consent for the publication of biographical details. In the case of adolescents under the age of 18 , their parent gave the consent for publication.

There was no funding for the study.

\section{Conflict of Interest}

The authors declare no conflict of interest.

\section{References}

1. Elgán TH, Leifman H (2013) Prevalence of adolescents who perceive their parents to have alcohol problems: A Swedish national survey using a web panel. Scand J Public Health 41: 680-683.

2. SAMHSA (2012) Data Spotlight: More than 7 Million Children Live with a Parent with Alcohol Problems.

3. Haber JR, Buchholz KK, Jacob TT, Grant JD, Scherrer JF, et al. (2010) Effect of paternal alcohol and drug dependence on offspring conduct disorder: gene-environment interplay. J Stud Alcohol Drugs 71: 652-663.

4. Ulrich I, Stopsack M, Barnow S (2010) Risiko- und Resilienzfaktoren von adoleszenten Kindern alkoholkranker 
Eltern: Ergebnisse der Greifswalder Familienstudie. Diskurs Kindheits- und Jugendforschung 5: 47-61.

5. Mellentin Al, Brink M, Andersen L, Erlangsen A, Stenager $E$, et al. (2016) The risk of offspring developing substance use disorders when exposed to one versus two parent(s) with alcohol use disorder: A nationwide, register-based cohort study. J Psychiatr Res 80: 52-58.

6. Sørensen HJ, Manzardo AM, Knop J, Penick EC, Madarasz W, et al. (2011) The contribution of parental alcohol use disorders and other psychiatric illness to the risk of alcohol use disorders in the offspring. Alcohol Clin Exp Res 35: 1315-1320.

7. Serec M, Svab I, Kolsek M, Svab V, Moesgen D, et al. (2012) Health*-related lifestyle, physical and mental health in children of alcoholic parents. Drug Alcohol Rev 31: 861-870.

8. Finan LJ, Simpson E, Schulz J, Ohannessian CM (2018) Parental problem drinking and emerging adult problem behavior: The moderating role of parental support. Journal of Child and Family Studies 27: 1175-1185.

9. Pönsch C (2012) Suchtkranke Eltern und Bindungsentwicklung der Kinder: Vom Durchbrechen transgenerationaler Verflechtungen. disserta Verlag, Hamburg.

10. Zobel M (2017) Kinder aus alkoholbelasteten Familien: Entwicklungsrisiken und Chancen. ( $3^{\text {rd }}$ edn), Hogrefe, Göttingen, Germany.

11. Brisch KH (2012) Treating attachment disorders: From theory to therapy. $\left(2^{\text {nd }}\right.$ edn), Guilford, New York, NY.

12. Velleman R, Templeton $L$, Reuber D, Klein M, Moesgen D (2008) Domestic abuse experienced by young people living in families with alcohol problems: Results from a crosseuropean study. Child Abuse Review 17: 387-409.

13. Mortazavizadeh Z, Forstmeier S (2018) The role of emotion regulation in the association of adult attachment and mental health: A systematic review. Archives of Psychology 2: $1-25$.

14. Carle A, Chassin L (2004) Resilience in a community sample of children of alcoholics: Its prevalence and relation to internalizing symptomatology and positive affect. Applied Developmental Psychology 25: 577-595.

15. Werner EE, Johnson JL (2004) The role of caring adults in the lives of children of alcoholics. Subst Use Misuse 39 699-720.

16. Carbonneau R, Vitaro F, Tremblay RE (2018) School adjustment and substance use in early adolescent boys: Association with paternal alcoholism with and without dad in the home. Journal of Early Adolescence 38: 1008-1035.

17. Mangiavacchia L, Piccoli L (2018) Parental alcohol consumption and adult children's educational attainment. Economics and Human Biology 28: 132-145.

18. Bennett LA, Wolin SJ, Reiss D (1988) Cognitive, behavioral, and emotional problems among school-age children of alcoholic parents. Am J Psychiatry 145: 185-190.

19. Hattie J (2009) Visible learning: A synthesis of over 800 meta-analyses relating to achievement. Routledge, New York, NY

20. Wang MC, Haertel GD, Walberg HJ (1993) Toward a knowledge base for school learning. Review of Educational Research 63: 249-294.

21. Corbin J, Strauss A (2008) Basics of qualitative research: Techniques and procedures for developing grounded theory. ( $3^{\text {rd }}$ edn), Sage, Thousand Oaks, CA.
22. Jellinek EM (1960) The disease concept of alcoholism. Hillhouse Press, New Haven, CT, US.

23. Bates ME, Pandina RJ (1992) Familial alcoholism and premorbid cognitive deficit: A failure to replicate subtype differences. J Stud Alcohol 53: 320-327.

24. Hinz LD (1990) College student adult children of alcoholics: Psychological resilience or emotional distance? Journal of Substance Abuse 2: 449-457.

25. Lester BM, Masten A, McEwen B (2006) Resilience in children. Vol 1094, Blackwell Publishing, Malden.

26. Park S, Schepp KG (2015) A systematic review of research on children of alcoholics: Their inherent resilience and vulnerability. Journal of Child and Family Studies 24: 12221231.

27. Kim HK, Lee MY (2011) Factors influencing resilience of adult children of alcoholics among college students. J Korean Acad Nurs 41: 642-651.

28. Pearson MR, D'Lima GM, Kelley ML (2011) Selfregulation as a buffer of the relationship between parental alcohol misuse and alcohol-related outcomes in first-year college students. Addict Behav 36: 1309-1312.

29. Arruda P, Santos MR (2011) Health production in adverse contexts: A study of the paths of coas. Online Brazilian Journal of Nursing 10: 1.

30. Moe J, Johnson JL, Wade W (2007) Resilience in children of substance users: In their own words. Subst Use Misuse 42: 381-398.

31. Molina BSG, Donovan JE, Belendiuk KA (2010) Familial loading for alcoholism and offspring behavior: Mediating and moderating influences. Alcohol Clin Exp Res 34: 1972-1984.

32. El-Sheikh M, Flanagan E (2001) Parental problem drinking and children's adjustment: Family conflict and parental depression as mediators and moderators of risk. J Abnorm Child Psychol 29: 417-432.

33. El-Sheikh M, Buckhalt JA (2003) Parental problem drinking and children's adjustment: Attachment and family functioning as moderators and mediators of risk. J Fam Psychol 17: 510-520

34. Hinrichs J, DeFife J, Westen D (2011) Personality subtypes in adolescent and adult children of alcoholics: A two part study. J Nerv Ment Dis 199: 487-498.

35. Bröning S, Kumpfer K, Kruse K, Sack PM, Schaunig-Busch I, et al. (2012) Selective prevention programs for children from substance-affected families: A comprehensive systematic review. Subst Abuse Treat Prev Policy 7: 23.

36. Jenson JM, Bender KA (2014) Preventing child and adolescent problem behavior: Evidence-based strategies in schools, families and communities. Oxford University Press, Oxford, UK.

37. Schroeder JL, Johnson GE (2009) Accessing substance abuse prevention programs for schools. Intervention in School and Clinic 44: 234-240.
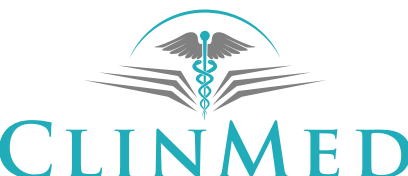

INTERNATIONAL LIBRARY 